\title{
Perpetrators and Princesses: Transgression and Subject Formation in Killing Aurora and Queen Kat, Carmel and St. Jude Get a Life
}

\author{
Michelle de Villiers
}

\begin{abstract}
It would be difficult to overestimate the importance in modern Western culture of transgression in the name of an essential self. (Author's emphasis)
\end{abstract}

(Dollimore 1991, p.39)

$\mathrm{T}$ ransgressive acts and transgressive states of being are integral to fictions of development, or 'coming of age' novels. In their representation of subjectivity and its formation such texts generally depict characters in the process of moving from narcissistic states of solipsism towards more socially acceptable forms of subjectivity. Whether the outcome of this trajectory is successfully attained or not may depend on whether transgressive acts are productive or counterproductive, and hence how these two distinct modes of transgression contribute to agential and abject forms of being, respectively. Representations of either mode in literature are inextricably bound up with narrative representations of selfhood and, since the dominant model of maturation in Western cultures valorises cooperative intersubjectivity, within the context of contemporary adolescent fiction transgression is still primarily used to reinscribe the characters within the dominant ideological framework of such a culturally privileged subjectivity. Transgression, however, can also function to interrogate social and cultural ideologies and, when used in more unorthodox ways, textual representations of transgression may actually serve to undermine and subvert such ideologies and their associated discursive practices.

In the wake of poststructuralist and postmodernist theories it is now generally recognised that reality is a social construct accessible only through the discourses we have available to make sense of $i t$, and that ideology shapes the consciousness of those subject to it in that it provides the means, or discourses, by which they make sense of the world and their place in it. As such, any author is 'a complex and variable function of discourse' (Foucault 1993, p. 123) and thus any individual creative act (the literary text, for example) is actually a manifestly social act which produces a cultural product carrying the resonances and meanings of the non-individual discourse on which it draws for expression. This inevitable imbrication of literature in social attitudes and ideologies results in its commitment, whether explicitly or implicitly, to the acculturation of its audience (Stephens 1995, p.
264). As Perry Nodelman has observed, literary texts are not only expressions of prevalent cultural values and assumptions, but also a significant way of embedding readers in these values and assumptions (1996, p.69).

Since Western culture and society are, to a large extent, predicated on the ideology of the individual, an ideology which valorises individuality, self-fulfilment, self-reliance and personal development, it is not surprising that the issues of development and selfhood are major themes in literature in general and.in children's and adolescent fiction in particular. Indeed, as Stephens argues, the educational and domestic ideological paradigms of most Western societies support the notion of children growing towards a state of being which is 'reasonable, creative, autonomous and achieving' (1992, p.120). Childhood and adolescence, then, are perceived as transitional stages which should lead from a solipsistic state to one of intersubjectivity, and such ideological assumptions are usually implicit in literature produced specifically for children and adolescents. Nodelman refers to this socialising intention as a 'colonisation' of children, 'to make them believe that they ought to be the way adults would like them to be' (1996, p.82). This preoccupation with selfhood and concomitant notions of acceptable behaviour and states of being, in conjunction with the overt socialising function of children's literature, effectively mediate and shape the functions of represented transgression in Australian children's narratives today.

Transgression itself is construed as an act of subverting, inverting or breaking existing codes, conventions, rules and structures. Indeed, transgression and transgressive behaviour are predicated on the very existence of these social, cultural and ideological practices which essentially curtail and constrain an individual's actions, thoughts. speech and ultimately, then, their sense of identity (McCallum 1999, p.118). Subsequent agency would appear to constitute actions, thoughts and speech which conflict with established social, cultural and ideological practices, that is, necessitate transgression. However, 
transgressive behaviour, as McCallum suggests, does not in itself necessarily constitute agency, for the very act of resistance implies subjection to that which is resisted. This concept, encapsulated in theories of a subjectivity defined as one's sense of personal identity or individual being in the world, has been formulated through contemporary psychoanalytic, philosophical, sociological and linguistic critiques. McCallum proposes that this sense of personal identity is constructed through the interplay of two ideologies, namely subjection and agency, that is, one is subject to the coercion of prevailing dominant ideologies and discursive practices on the one hand and, on the other, in a position to resist such ideological and discursive pressure through conscious and deliberate thoughts and actions $(1999$, p.4). Obviously then, there appears to be a direct correlation between transgression and agency, but transgression is also implicated in processes of subjection. This fact points to the existence of two distinct modes of transgression in relation to the subject: transformative and productive transgression which leads to agency; and self damaging or counter-productive transgression which leads to abjection. Both these modes of transgression are categories of personal experience and action which are generated via the social construction of subjectivity (McCallum 1999, p.119).

In Helen Barnes' Killing Aurora and Maureen McCarthy's Queen Kat, Carmel and St Jude Get a Life, representations of transgressive forms of behaviour or being, whilst functioning as an intrinsic element of subject formation, simultaneously provide a position from which to interrogate existing cultural and societal hegemonic structures-dominant ideologies, their naturalising discourses and the effects on experience, action and subjectivity (McCallum 1999, p.118). However, since one of the fundamental aims of children's literature is to 'inculcate socially desirable ideological positions' in its readers (Stephens 1995, p.263), textual representations of transgression in Australian children's literature, while used to subvert or interrogate social codes and structures which form the moral, political, and ethical boundaries of society, are more often than not reassimilated into the hegemonic model of maturation in Western cultures. This model valorises cooperative intersubjectivity, and thus transgression ultimately functions to promulgate a social ideology which is conservative and traditional. McCarthy's Queen Kat. Carmel and St.Jude Get a Life exemplifies such an inherently conservative novel, whereas Bames' Killing Aurora makes a far more radical use of transgression which questions the dominant social and cultural paradigms of identity formation and, also, the very existence of any transcendent ethical or moral behaviour.

The central characters of Killing Aurora and Queen Kat, Carmel and St Jude Get a Life are all female and both novels are fictions of development, female versions of the historical and theoretical Bildungsroman genre, in which the primary assumption is the evolution of a coherent self predicated on individual achievement and social integration (Abel et al 1983, p.5). Abel stresses that gender is a crucial issue in considering any particular Bildungsroman since the sex of the protagonist affects every aspect of a literary representation of development. Indeed, the restraints of codified rules and mechanisms of control, ranging from established societal norms to sociopolitical laws, are vastly different for men and women in society, and it follows that the representation of a woman's developmental trajectory and her transgressive behaviour and states of being in this process will assume particular forms based on the discourses which inform her journey to selfhood. As such, Barnes' and McCarthy's novels actively engage with dominant gender ideologies, and discourses of femininity and the body are therefore major themes of both texts. Many contemporary feminist theorists have stressed that the body, as a discursive construction fully imbricated with and constituted by systems of meaning, signification and representation, is crucial to any understanding of woman's psychical and social existence (Grosz 1994, p.18). In Queen Kat, Carmel and St Jude Get a Life and, far more markedly, in Killing Aurora, the body as subjective tertitory becomes a locus of ideological inscription, functioning as a site of resistance, transgression, compliance and agency.

A powerful social effect of ideologies is to render natural. and therefore to legitimise, what are in fact historically specific, not universal, social structures, practices and their associated ideas, and the Western preoccupation with fat, diet and slenderness appears to function as one of the most powerful normalising discursive strategies of late capitalism. The body effectively demonstrates what 
are considered correct or incorrect attitudes toward the demands of the normalising discourse and, in the anorectic, the rebellion against normalisation actually pays homage to the dominant cultural values but outdoes them in their own terms. The anorectic, as Bordo suggests, excels at her/his own rules but, in so doing, exposes the hidden penalties of doing so (1990, p.100). In Killing Aurora, the eponymous hero's transgression, in living by her own rules, is actually played out through her body in response to this normalising discourse of slenderness-Aurora believes that she, like her cartoon hero Elektra 'is what she looks like' (p.87) and that 'you can do anything you like and say anything you want, if you're thin' (p.48). She thus conflates adherence to the dominant cultural ideal of beauty with selfhood and agency when, in reality, she is actually firmly constrained by discursive agents of control which express disapprobation of fat and applaud the thinner and more socially acceptable body. Aurora's mother, her step-father, and boys who comment on her 'barge-arse' all function as such agents, as do the advertising billboards, teen magazines, and other popular representations of the body through which meaning is symbolised, encoded and transmitted.

Ideologies, as Foucault has articulated, reach into experience and identity re-emerging as 'voluntary' selfoppression. (in Dollimore 1991, p.181). This effect is evident in Killing Aurora in a highly exacerbated form and embodied by the tape worm or Dirty Creature inside Aurora's head which begins to control the way she thinks about herself. In 'telling' her she is ugly, fat, and a beast, it effectively controls her lived experience. The tape worm is clearly metonymic of Western ideologies of the body and femininity, and when it (and they) gain complete control of Aurora she suffers a total loss of agency, being remade, reshaped and ultimately consumed; 'When there's no fat left to burn, the Dirty Creature will start to select from her hidden organs. So secretly, silently, she begins to consume herself, to disappear into herself, into nothing' (p.180, my italics,). Through Aurora's eating disorder which represents transgressive behaviour leading to abjection, the text not only effects a quite explicit critique of the controlling discursive mechanisms and their destructive consequences for the subject, but also of the transgressive behaviour itself. Killing Aurora, by continually drawing attention to the fact that Aurora's behaviour is destructive and self-defeating, forcing her, as it does, into pronounced and alienating solipsism, effectively pejorates such transgression since such behaviour does not support an ideologically privileged type of subjectivity. Aurora's transgression signifies a loss of control and throughout the novel she is alienated from those who care for and about her, feels cold and homeless and unable to move or speak: by effacing herself physically she effectively effaces her own identity and denies herself a subject position.

In keeping with Barnes' more radical use of transgression, Aurora's recuperation from her abject state (foraging for food in the garbage, becoming a 'parody of Death' with dry parchment skin, exophthalmic eyes, hairy chest and back), does not begin with her counselling sessions with an older male psychiatrist who is representative of a distinctive dominant patriarchal paradigm. Instead, it begins with Web who draws Aurora into the field of her own transgressive behaviour. They go on 'obscure [and highly illegal] graffiti missions' and Aurora's cautious reactionthat they may get into trouble-is countered by Web's pragmatic and telling response of 'we are in trouble already, especially you' (p.190). In this way Web draws attention to the fact that moral and ethical 'truths' are not necessarily all important or immutable, and certainly not transcendental. 'What's legal,' Web contends 'is not always right, look at napaim and nukes.' Aurora begins to feel 'just the tiniest bit good' (p.191) because she is breaking her own ultimately destructive rules by spending time with Web and thus moving from a state of solipsism towards intersubjectivity. For the first time ever, she recognises 'that maybe she is not the most crucial thing in the world'(p.216). Whilst Aurora's abjection is as a result of a mode of transgressive behaviour. her agency and development of a confident subjectivity are also predicated on transgression: her illegal activities with Web; the destruction through fire of the domestic space which has come to imprison her; her refusal to reoccupy this domestic space by going to live with her aunt; and her revisioning as a plump Goth girl. The realisation that she will never be 'the right shape' and that 'staying alive is crucial' allows Aurora to laugh at her brand-new (culturally unacceptable) buxom body because, although the desire to be thin is still there, she is aware she can't afford it. There 
is no euphoric and utopian conclusion for Aurora who is still very much caught in a framework of ideological inscription. Her acknowledgement of this, however, enables resistance of it and entry into a 'vast and unbordered' land where an active and more confident subjectivity is possible.

In contrast to Aurora, who initially loses control through transgression, the character of Web is seen to gain control of her life and consolidate her subjectivity through being transgressive. Throughout the text Web is allied very strongly with elemental, chaotic and violent forces, in particular the motif of fire. And her transgressive behaviour and being is often articulated through thismotif. Herposition in opposition to traditional notions of femininity is signalled early in the text and initially deployed through a subversion of traditional fairytale imagery. Whilst the making of a princess, as perceived by Web's and Aurora's contemporaries, is effected through weight loss, 'fire was the first princess Web believed in' (p.39) and it is the princess of fire, not the princess of disappearing, who ultimately has restorative and transformation powers. Just as Aurora's destruction of the family home by fire is implicitly validated by the text, Web's often violent actions are represented as transformative and productive forms of transgression which lead to agency: when Fern's 'Friday night root' comes around Web blows up his car, finding enormous pleasure and release in the all engulfing flames which metaphorically swallow up the destructive and constraining elements in her life and allow her to 'fling herself headlong into things' (p.179). After being enjoined by her Pop to 'be your own girl' ( $p .123$ ), she tears up and bums her absent mother's photo; and on learning that her Pop has been consigned to a home for the aged, she smashes bottles on the pavement outside her house, the action enabling her to gain control of her emotions and make her feel 'too strong. for tears' (p.149). Even her intersubjective relationshipsare forged through transgression. Her friendship with Aurora is consolidated through their illegal activities, her relationship with her sister Fern is reestablished through a shopping expedition which ends in the two girls acting inappropriately and being asked to leave the store, and the relationship with her largely absent and apathetic father is recuperated when she threatens to bum down the shed to which he has withdrawn. Her father is forced to emerge- 'I'm here now. I'm listening' (p.228)and so it is Web's transgressive behaviour which reunites the two and leads to a more cooperative and incipiently intersubjective relationship between them.

Web's character is often explicitly antagonistic toward traditional notions of femininity, and many of her transgressive actions work expressly to expose and subvert the constraining strategies of this discourse. She rejects lipstick because she recognises its overt sexualising and feminising function and her appearance in general does not conform to the traditional feminine paradigm. She adopts aggressively anti-feminine clothes and, by cutting up the clothes bought by Aunt Lorene, violently resists attempts to assimilate her into the realm of what is deemed appropriate for teenage girls. For Web, the ideological construction of women through discourses of femininity and the body is tantamount to entrapment and loss of agency. The young girls she knew as friends in primary school have now turned into 'strange, quiet creatures' who wear smiling masks, and Web conceives of these girls as psychically trapped, stuck inside their new docile bodies. When Web responds to Aurora's dismay at looking fat in her school uniform by saying 'that's what all the dumb chicks say' and referring ironically to the teen magazine Sweetheart as Thick Tart, calling Aurora's attention instead to The Semiotics of Mythology for Beginners which reveals the implicit connection between women and dragons (because females are 'supposed to represent the chaotic and disorderly elements of life' ( $p .42$ ), it is evident that her transgression actually functions to construct a counter-discursive strategy within the text. Web is not only rejecting the outer trappings of femininity but also actively interrogating the underpinning ideological assumptions of such a discourse. Such agency, predicated as it is on transgression, has penalties however. In flouting the hegemonic normalising strategies supporting feminine ideology Web is cast as abnormal, a backward, butch weirdo and misfit. For her peers, Web is abject, and her move toward intersubjectivity must be forged in spite of this and with the help of people like her Pop who recognise that, although 'a square peg will fit in a round hole if you bash it hard enough' (p. 121), one must resist such forced conformity.

Web also rejects the patriarchal assumption 'boys will be boys', actively confronting the workmen who tease Aurora. Finding words inadequate, however, she decides 
to blow up the whole construction site but this violence does not, in fact, transpire. Web'stransgressive tendencies are mitigated by the realisation that 'there isn't enough fire power in the world to get rid of all of this' (p.202) and, in the end, the fires and bombs are relinquished for far more subversive activities. Web's and Aurora's graffiti missions circumscribe quite complex forms of transgression; by defacing advertising billboards and others' phaliocentric graffiti they draw attention to the status of these images as semiotic texts and, in so doing, subvert and undermine the original messages of these images which have had such destructive and disturbing effects, particularly on Aurora.

In comparison to Barnes' novel, the function of transgression in Queen Kat. Carmel and St Jude Get a Life is, in many ways, less complex and less subversive. Although the two modes of transgression in the process of subject formation are apparent in McCarthy's novel, and transgression is used to interrogate the social and cultural discourses of the body and of femininity, transgressive behaviour and states of being are used predominantly to reinscribe the characters within the dominant ideological framework of socially cooperative subjectivity. As Cart has pointed out, the didactic possibilities offered by novels for moral and other instruction have tempted some writers to confuse realistic fiction with problem-novel-tract (1996, p.65) and Queen Kat, Carmel and St Jude Get a Life, in its sometimes almost earnest didacticism, is in many ways a celebration of conventional morality. Indeed, in order for the characters to move toward 'healthy' states of subjectivity, it is necessary for all three to repudiate their transgressive tendencies.

In Queen Kat, Carmel and St Jude Get a Life, as in Killing Aurora, the body is treated as an inscriptive surface indicative of the fact that, as Stephens suggests, 'self identity is defined by how an individual is valued by others' $(1999$, p.5). Western cultures of overabundance have morally coded the fat/slender body, the slender body signifying self-control and moral fortitude, and the fat body signifying moral or personal inadequacy, laziness, greed and lack of will power (Bordo 1990, p.94). Carmel who is very conscious of being overweight, recognises this inscription, knowing that 'this body, this place I' $\mathrm{d}$ been forced to inhabit all my life was so far from the accepted ideal of beauty that I knew I would never... measure up' (p.55). Excessive weight, perceived as rebellion against normalisation and therefore as an affront to dominant cultural values, often inspires hostility. In Carmel's case her transgressive behaviour in the novel is largely instigated by such hostility. When a boy she admires at college lets loose a vitriolic tirade, castigating her for being fat and 'disgusting,' Carmel misses college classes, spends her brother's rent money on clothes in an attempt to transform herself and, longing to make herself different from her 'simple, old-fashioned, boring family' (p.82), suspends the 'simple moral code' with which she has grown up and begins to shoplift. Unlike Web in Killing Aurora, who finds unrestrained and 'glorious' pleasure in the experience of shoplifting, Carmel's guilt manifests itself in a nervousness which invariably results in her inability to steal anything of real use to her. Although she is desperately trying to establish her own identity as something separate from her life back in Manella and, in so doing, attempting to gain a more self reliant subjectivity, her transgressive behaviour actually functions to negate agency since it leads to secrecy and increased solipsism. When she eventually sees a tearful girl being arrested for shoplifting she is scared that 'that could be me!' (p.83) and abandons her illegal activity. As such, the representation of transgression functions to constrain Carmel morally since she remains transfixed within the law.

Similarly, the 'blunt and fairly tough' Jude (p.185), whose selfhood appears to be quite assured and wellgrounded, moves rapidly toward a state of abjection when she begins to stalk Orlando, the man who ordered and probably oversaw her father's torture and death in Chile. As a consequence of this obsessive (and hence, transgressive) behaviour, she misses her university classes, stops eating properly to the point where she undergoes sudden weight loss, gets more and more withdrawn and quiet, and neglects her formerly close relationship with her mother, refusing to read Cynthia's letters or even take her calls. Throughout this experience, which leads Jude into a profound and self-defeating state of solipsism, she has 'an odd feeling of moving backwards' (p.271) and knows that what she is doing is 'useless, dangerous, ...wouldn't get [her] anywhere' ( $p .280$ ), revealing the implicit assumption that confinement to inner life threatens 
a loss of public activity and, therefore, a loss of agency. It is when Jude decides to kill Orlando, and thus contravene a powerful and well-established moral code, that her world spirals out of control. Her recuperation is effected only when Cynthia comes to Melbourne and looks after her daughter thereby restoring their relationship and making Jude understand that 'to get rid of him [Orlando] would mean nothing' (p.289). When her mother leaves Jude feels as though she's 'just arrived on earth and ... had to work out what it meant to be alive' (p.292). Consequently, because she is 'past intimidation', she gets a tattoo and has all her hair chopped off in a men's barber shop, actions which are transgressive in that they work against the traditional paradigm of femininity and, simultaneously, agential in that they re-establish her sense of self and ground her subjectivity. To a certain extent Jude, like Carmel, remains transfixed within the law since, at the novel's conclusion, she is looking into the possibilities of pursuing legal action against Orlando rather than pursuing any form of nonconventional retribution.

Katerina (Kat), more than any other character, must repudiate her transgressive behaviours in order to achieve a strong and acceptable self identity. She is a girl who always looks as though she's stepped straight out of a magazine and, indeed, actually does feature in an issue of Vogue. As such, it is obvious that she subscribes to the prevailing ideal of beauty in society and, unlike Carmel, does not have to struggle for acceptance because, physically, she is the embodiment of dominant cultural values. However, the text positions readers to disapprove of her response that 'I'll get whatever I want' (p.354) because she 'could go a long way with a face like that' (p.353). This is an attitude indicative of her narcissism and self-regarding tendencies, tendencies which prevent cooperative interaction with others and thus negate a culturally privileged subjectivity. Kat's hedonistic lifestyle, which includes numerous sexual liaisons, some with older married men, drug usage and a calendar of 'soft core porn shots' (p.355), leads to a dissolution of self, an ungrounded subjectivity and alienation from others around her.

The text's representation of the legal, moral, ethical and emotional consequences of Kat's behaviour also function to reinscribe her within the dominant ideological framework, since all indicate that her transgression is selfdefeating and socially unacceptable: she is arrested and charged for possession of drugs, which threatens her future career as a lawyer; she can only extricate herself from this position by 'lagging on a good friend' ( $p .355$ ); she is 'more or less raped' ( $p .355$ ) by the photographer who takes the nude photos and subsequently infers that her behaviour legitimated such a response; she is alienated from her family and causes them considerable distress when they leam of her drug charges and see her half-naked photo in a tabloid newspaper. Disapprobation of her behaviour is also expressed through Jude who views the nude photos of Kat as 'embarrassing and tacky' (p.245) and 'a bit pathetic' (p.248). Jude also openly disapproves when she finds her snorting coke and Kat herself recognises that she has become 'ugly, horrible. No one wants to know me' (p.395), an image of herself she vows to remember in order to curtail her desire for illicit drugs.

Although Kat's character is used to question the dominant paradigm of beauty, her recuperation is instigated when she begins to exhibit other-regarding behaviour and takes Carmel's young twin brothers home for a fun afternoon in the pool. I would argue, then, that she is merely being reinscribed within the dominant patriarchal framework which aligns women with the stereotypically 'feminine' and 'natural' role of nurturing and caring for children. Her transgressive behaviours are invariably derided by the text, which insistently upholds traditional and conservative social and cultural values. Even the attempt to interrogate and undermine contemporary discourses of the body and femininity is mediated by the subtext of traditional romance. Jude and Carmel enjoy an affirming relationship in which Jude encourages Carmel not to conform to normalisation by dieting, but rather, to accept herself and her large body as beautiful. Subsequently, Anton, an archetypal romance hero-a young lawyer who is 'very male...fit and muscular' (p.149) and, conveniently, set to inherit a substantial rural property falls instantly in love with Carmel when he sees her sing, thus substantiating Jude's earlier claims that Carmel is beautiful, talented and sexy. Clearly, the hyperbolic nature of this highly contrived romance moderates and contains the effects of attempts to undermine traditional notions of femininity and the socially acceptable body. 
Textual representations of transgressive behaviour and states of being in Killing Aurora and Queen Kat, Carmel and St Jude Get a Life function as intrinsic elements of subject formation, in both productive and counterproductive modes, as well as working to question, subvert and undermine dominant ideological structures, their associated discursive practices and thus the boundaries of represented social codes. However, due to the socialising imperative of children's and adolescent fiction, the representation of transgression in much of this literature, as evidenced particularly by $Q u e e n$ Kat, Carmel and $S t$ Jude Get a Life, has an inherently conservative social function, co-opted as it is 'by an ideologically inscribed model of maturation which values socially cooperative forms of intersubjectivity' (McCallum 1999, p.118). Killing Aurora, although viewing reinscription of the subject within the framework and structures of the dominant as inevitable, does allow for genuine agential behaviour in terms of agency being 'the place from which resistance to the ideological is produced and played out'. As such, it is considerably more radical in its use of transgression. Consequently, the functioning of such representations has greater complexity and depth than those of McCarthy's novel and, unlike the majority of its contemporaries in Australian children's literature, it enables the polemic of Killing Aurora to retain the injunction, 'Be a perpetrator!' (p.435).

\section{REFERENCES}

Abel, Elizabeth, Hirsch, Marianne \& Langland, Elizabeth (eds) (1983) The Voyage In: Fictions of Female Development. Hanover and London, University Press of New England.

Barnes, Helen (1999) Killing Aurora. Ringwood, Victoria, Penguin Books.

Bordo, Susan (1990) 'Reading the Slender Body', in Jacobus, M., Fox Keller, E. and Shuttleworth, S. (eds) Body/Politics: Women and the Discourses of Science. New York and London, Routledge, pp. 94-5.

Cart, Michael (1996) From Romance to Realism: 50 Years of Growth and Change in Young Adult Literature. New York, HarperCollins.

Dollimore, Jonathan (1991) Sexual Dissidence: Augustine to Wilde, Freud to Foucault. Oxford, Clarendon Press.

Foucault, Michel (1993) 'What is an Author?', in Wolff, J., The Social Production of Art. London, Macmillan, p. 123 [1979].

Grosz, Elizabeth (1994) Volatile Bodies: Toward a Corporeal Feminism. Sydney, Allen \& Unwin.

Lanser, Susan Sniader (1992) Fictions of Authority: Women Writers and Narrative Voice. Ithaca and London, Cornell University Press.

McCallum, Robyn (1999) Ideologies of ldentity in Adolescent Fiction. New York and London, Garland Publishing.

McCarthy, Maureen (1995) Queen Kat, Carmel and St Jude Get a Life. Ringwood, Victoria, Penguin Books.

Nodelman. Perry (1996) The Pleasures of Children's Literature. Second edition. New York, Longman.

Scutter, Heather (1999) Displaced Fictions: Contemporary Australian Books for Teenagers and Young Adults. Melbourne, Melbourne University Press.

Shildrick, Margrit (1997) Leaky Bodies and Boundaries: Feminism. Postmodernism and (Bio)Ethics. London and New York, Routledge.

Stephens, John (1995) 'Children's literature, value, and ideology', Australian Library Review 12, 3, 255-265.

Stephens, John (1999) 'Construction of female selves in adolescent fiction: makeovers as metonym', Papers: Explorations into Children's Literature 9,1, 5-13.

Stephens, John (1992) Language and Ideology in Children's Fiction. London and New York. Longman.

\section{BIOGRAPHICAL NOTE}

Michelle de Villiers is currently studying in the Creative Arts program at Macquarie University. Her area of specialisation is Creative Writing with other areas of interest being English and Cultural Studies. She would like to thank John Stephens for his encouragement and support with regard to this paper.

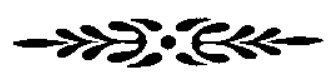

